\title{
Comparison Different Automated Systems for Detection of Penicillinase in Staphylococcus Aureus
}

\author{
Kai-sen Chen ${ }^{1}$, Shirong Lin' ${ }^{2}$, Pei-qun Li ${ }^{3}$, Xia Dong ${ }^{4}$, Dong Luo ${ }^{5}$ and Wei Zhang ${ }^{6}$ \\ ${ }^{1}$ Department of Clinical Laboratory, The First Affiliated Hospital of Nanchang University, NanChang, Jiangxi, China \\ ${ }^{2}$ Department of Emergency, The First Affiliated Hospital of Nanchang University, NanChang, Jiangxi, China \\ ${ }^{3}$ Department of Clinical Laboratory, The First Affiliated Hospital of Nanchang University, NanChang, Jiangxi, China \\ ${ }^{4}$ Department of Clinical Laboratory, The First Affiliated Hospital of Nanchang Univsrsity, NanChang, Jiangxi, China \\ ${ }^{5}$ Department of Clinical Laboratory, The First Affiliated Hospital of Nanchang University, NanChang, Jiangxi, China \\ ${ }^{6}$ Department of Clinical Laboratory, First Affiliated Hospital of NanChang University, China
}

*Corresponding author: Wei Zhang, Department of Clinical Laboratory, First Affiliated Hospital of NanChang University, 17 Yongwaizhengjie, Nanchang, 330006, China, Tel: +86 18970968159; Fax: +86 79188623153; E-mail: Zhangweiyfy@126.com

Received Date: May 13, 2017; Accepted Date: May 23, 2017; Published Date: May 27, 2017

Copyright: (C) 2017 Chen K, et al. This is an open-access article distributed under the terms of the Creative Commons Attribution License, which permits unrestricted use, distribution, and reproduction in any medium, provided the original author and source are credited.

Citation: Chen K, Lin S, Li P, et al. Comparison different automated systems for detection of penicillinase in Staphylococcus aureus. Br J Res 2017, 4: 12.

\section{Abstract}

The accuracy of Vitek 2, WalkAway 40, and DL-96 systems for susceptibility testing of penicillin against 547 S. aureus was evaluated using broth micro dilution. BlaZ gene was taken as gold standard to predict penicillinase-producing or not. Overall, there are no very major error in Vitek 2, one in WalkAway 40 and seven in DL-96. No major errors and 59 minor errors were noted in this study. The results showed that Vitek 2 had more reliable rate to predict penicillinaseproducing S. aureus.

\section{Introduction}

S. aureus is still common etiological agents involved in almost all tissue infections. Since the penicillinase-producing $S$. aureus was first isolated in 1940s, infections caused by penicillinresistant strains with sharply increase in the world [1]. In China, almost $10 \%$ S. aureus clinical isolates were considered penicillin resistant in recent years $[2,3]$. Because of its narrow spectrum and low cytotoxicity, it is usually valuable for penicillin to cure penicillin susceptible $S$. aureus isolates [4]. However, a false positive penicillinase report might result in potentially misleading therapy for the pathogen infection. CLSI recommends supplemental tests should be performed even penicillin $\mathrm{MIC}(\leq 0.12 \mathrm{mg} / \mathrm{L})$ in drug sensitive range [5]. In China, many commercial automated systems for microbial susceptibility testing are widely used in clinical microbiology laboratories in recent years, including imported automated systems (such as Vitek 2 system, bioMerieux, Lyon, France; Microscan WalkAway-40 Plus, Siemens company, Berlin, German) in some tertiary hospitals [6,7] and Chinese domestic medical systems (such as DL-96, Zhuhai Dier company, Zhuhai, China) in small and medium-sized hospitals. Although the Ministry of Health of China each year perform external quality control for improving these instruments detecting results, technicians pay more attention to correct pathogens, identification, and antimicrobial susceptibility results more depend on manual methods. As a result, it is necessary to assess whether these instruments can offer accurate antimicrobial susceptibility testing (AST) reports or not.

\section{Aim of the Study}

The aim of this study is to evaluate the susceptibility testing of penicillin of the vitek 2 AST-67 card, WalkAway P33 panel and DL-90 positive panel for $S$. aureus isolates. We collected 550 clinically significant S. aureus isolates during January 2010 to December 2015 from different hospitals in China. All strains were re-identification as previously described [8], penicillin susceptibility testing using broth micro dilution method referenced by CLSI and $\beta$-lactamase detection using blaZ gene PCR [9]. The amplified primers blaZ-F: 5 'TTCAACACCTGCTGCTTTCGG-3' and blaZ-R:5 'CCTTCATTACACTCTTGGCGGTTTC-3' were designed based on the penicillin enzyme gene [10]. Amplification conditions: $5 \mathrm{~min}$ at $94 ; 30 \mathrm{~s}$ at $94,45 \mathrm{~s}$ at $58,30 \mathrm{~s}$ at 72 for a total of 30 cycles, and finally extends for $7 \mathrm{~min}$. The amplified product was determined by $2 \%$ agarose gel electrophoresis. At the same time, we assessed percentages of agreement in clinical categories, including essential agreement (EA) [the same MIC values (within \pm 1 dilution) were obtained by the automated systems and the reference method], categorical agreement (CA) (test MICs interpreted within the same susceptibility category as the reference method), very major error (VME) (resistant by the reference method but susceptible by the test method), major error (ME) (susceptible by the reference method but resistant by the test method), and minor error ( $\mathrm{mE}$ ) (susceptible or resistant 
by either the reference or the test method but intermediate by the other method). These results were not thought to disagree when MICs determined by reference micro dilution were under or over the limit concentrations in the automated panels, these results were never considered to disagree.

\section{Result}

During our study period, 547 S. aureus isolates were considered as correct identification, 3 were misidentified, including one in each instrument. According to the AST results of these systems, there were 247 (45.2\%) penicillin-susceptible,
300 (54.8\%) penicillin-resistant strains. However, the results would be revised with 261 (47.7\%) penicillin-susceptible and 286 (52.3\%) penicillin-resistant strains by reference method. Compared with reference method, the Vitek 2 EAs was $91.5 \%$ and CAs was $94.5 \%$, the WalkAway 40 EAs was $85.0 \%$ and CAs was $90.2 \%$, the DL-96 EAs was $80.2 \%$ and CAs was $85.0 \%$ (Table 1). There were no MEs with these automated systems. There were only $12 \mathrm{mEs}$ with Vitek 2, WalkAway 40 resulted in 19 discrepancies (18 mEs and 1 VMEs) and DL-96 had 7 VMEs and $29 \mathrm{mEs}$ (Table 1), which meant Vitek 2 had more accurately detecting results, consistent with literature [11].

Table 1: Summary of the results obtained with automated methods compared to the results of reference micro dilution assay.

\begin{tabular}{|c|c|c|c|c|c|c|c|c|c|c|}
\hline \multirow{2}{*}{$\begin{array}{l}\text { Automated } \\
\text { systems }\end{array}$} & \multirow{2}{*}{$\begin{array}{l}\text { System } \\
\text { (concns in } \mathrm{mg} / \\
\text { liter) }\end{array}$} & \multicolumn{4}{|c|}{ No.of Isolatesa } & \multirow{2}{*}{$\begin{array}{l}\text { EAb } \\
\text { (no.[\%]) }\end{array}$} & \multirow{2}{*}{$\begin{array}{l}\text { CAc } \\
\text { (no.[\%]) }\end{array}$} & \multirow{2}{*}{$\begin{array}{l}\text { VMEd } \\
\text { (no.[\%]) }\end{array}$} & \multirow{2}{*}{$\begin{array}{l}\text { MEe } \\
\text { (no.[\%]) }\end{array}$} & \multirow{2}{*}{$\begin{array}{l}\text { mEf } \\
\text { (no.[\%]) }\end{array}$} \\
\hline & & Total & $\mathbf{R}$ & I & s & & & & & \\
\hline Vitek 2 & $\begin{array}{l}0.125, \quad 0.25, \quad 1 \\
2,8,64\end{array}$ & 184 & 89 & 0 & 95 & 91.5 & 94.5 & 0 & 0 & $12(6.5)$ \\
\hline 40 Plus & $\begin{array}{l}0.03,0.12,0.25 \\
2,8\end{array}$ & 196 & 123 & 0 & 73 & 85.0 & 90.2 & $1(0.5)$ & 0 & $18(9.2)$ \\
\hline DL-96 & $\begin{array}{l}0.12,0.25,1.0 \\
2.0\end{array}$ & 167 & 88 & 0 & 79 & 80.2 & 85.0 & $7(4.2)$ & 0 & $29(17.4)$ \\
\hline
\end{tabular}

${ }^{a}$ R: resistant; I: intermediate; S: susceptible; ${ }^{b} \mathrm{EA}$ : essential agreement (MIC within \pm 1 doubling dilution); ${ }^{\mathrm{C} C A}$ : categorical agreement; ${ }^{\mathrm{d} V M E}$ : very major error; ${ }^{\mathrm{e}} \mathrm{ME}$ : major error; ${ }^{f} \mathrm{mE}$ : minor error.

Table 2: Comparison three automated systems penicillin value with broth micro dilution and blaZ gene.

\begin{tabular}{|c|c|c|c|c|c|c|c|c|c|c|c|c|}
\hline \multirow{4}{*}{$\begin{array}{l}\text { Penicillin } \\
\text { MIC }^{a} \\
(\mathbf{n}=547)\end{array}$} & \multicolumn{12}{|c|}{ No of isolates } \\
\hline & \multicolumn{6}{|c|}{ blaZ positive } & \multicolumn{6}{|c|}{ blaZ negative } \\
\hline & \multicolumn{2}{|c|}{$\begin{array}{l}\text { Vitek } 2 \\
(n=75)\end{array}$} & \multicolumn{2}{|c|}{$\begin{array}{l}40 \text { Plus } \\
(n=130)\end{array}$} & \multicolumn{2}{|c|}{$\begin{array}{l}\text { DL-96 } \\
(n=87)\end{array}$} & \multicolumn{2}{|c|}{$\begin{array}{l}\text { Vitek } 2 \\
(n=89)\end{array}$} & \multicolumn{2}{|c|}{$\begin{array}{l}40 \text { Plus } \\
(n=64)\end{array}$} & \multicolumn{2}{|c|}{$\begin{array}{l}\text { DL-96 } \\
(n=80)\end{array}$} \\
\hline & $0^{b}$ & $0^{c}$ & $0^{\mathrm{b}}$ & & $0^{b}$ & & $4^{b}$ & $4^{c}$ & $2^{\mathrm{b}}$ & & $7^{b}$ & \\
\hline 0.03 & 2 & 2 & 4 & $6^{c}$ & 1 & & 31 & 31 & 17 & $23^{c}$ & 15 & \\
\hline 0.06 & 5 & 6 & 3 & & 3 & & 24 & 26 & 18 & & 28 & \\
\hline 0.12 & 4 & 5 & 12 & 11 & 9 & $10^{c}$ & 39 & 25 & 17 & 34 & 16 & $66^{c}$ \\
\hline 0.25 & 6 & 7 & 16 & 27 & 15 & 23 & 2 & 2 & 5 & 6 & 2 & 5 \\
\hline 0.5 & 7 & 6 & 10 & & 10 & & 0 & 0 & 2 & & 5 & \\
\hline 1.0 & 6 & 5 & 7 & & 9 & 11 & 0 & 0 & 1 & & 6 & 8 \\
\hline 2.0 & 5 & 6 & 11 & 26 & 7 & 43 & 1 & 1 & 2 & 1 & 0 & 1 \\
\hline 4.0 & 6 & 7 & 11 & & 7 & & 0 & 0 & 0 & & 0 & \\
\hline 8.0 & 8 & 5 & 16 & 61 & 8 & & 0 & 0 & 0 & 0 & 0 & \\
\hline 16.0 & 10 & 9 & 17 & & 9 & & 0 & 0 & 0 & & 1 & \\
\hline 32 & 5 & 6 & 14 & & 3 & & 0 & 0 & 0 & & 0 & \\
\hline 64 & 11 & 11 & 12 & & 6 & & 0 & 0 & 0 & & 0 & \\
\hline
\end{tabular}

In order to gain a better understanding correctness of these systems about to predict penicillinase production or not, blaz gene was taken as the gold standard to evaluate. The results showed that false positive rate was $1.8 \%(3 / 164)$ and false 
negative rate was $6.0 \%(11 / 184)$ in Vitek $2,5.1 \%(10 / 196)$ and $10.0 \%(19 / 196)$ in WalkAway $40,8.4 \%$ (14/167) and $7.8 \%$ $(13 / 167)$ in DL-96, respectively (Table 2). There was no significant difference between these instruments in false negative rate, but significantly higher in DL-96 than vitek 2 in false positive rate $\left(\chi^{2}=6.59, P=0.01\right)$. Additionally, vitek 2 had 91.5\% (150/164), WalkAway 40 had 85.2\% (167/196) and DL-96 had $83.8 \%(140 / 167)$ coincidence rate, there are no obviously difference among them.

Because of a limited concentration number (sometimes discontinuous scales) for penicillin detection in these panels or cards, automated systems with advanced expert systems can potentially enhance the reproducibility and the reliability of test results [11]. For example, penicillin detecting hole in vitek 2 has 5 concentration gradient, including $0.125,0.25,1,2,8,64 \mathrm{mg} / \mathrm{L}$, respectively. Because of high photoelectric colorimetry sensitivity and intelligent calibration system, Vitek 2 could detect wide range penicillin concentration, from 0.015 to over $64 \mathrm{mg} / \mathrm{L}$. Consequently, these reports can offer more excellent reports to improve the quality of patient care. Although WalkAway 40 has 5 different penicillin detecting hole, including $0.03,0.12,0.25,2$ and $8 \mathrm{mg} / \mathrm{L}$, respectively, because of lack intelligent calibration system, there is only 5 report model, including $0.03,0.12,0.25,2$ and $8 \mathrm{mg} / \mathrm{L}$. Compared with broth micro dilution, the coincidence rate was $85.0 \%(165 / 194)$, however, owing to instrument operation convenience, many customers choose the system. DL-96 system is China's domestic microbial instruments, only 4 measuring hole, including $0.12,0.25,1.0$ and $2.0 \mathrm{mg} / \mathrm{L}$, respectively, there is only 4 report model, as a result, the coincidence rate was only $80.2 \%(134 / 167)$ compared with broth micro dilution.

\section{Conclusion}

In conclusion, the results of this study considered that vitek 2 has most reliable rate for susceptibility testing of penicillin in $S$. aureus because of its excellent expert system. DL-96 had only $80.2 \%$ coincidence, but it could meet most clinical requirements in detecting penicillin susceptibility in S. aureus. In a word, each automated system has its advantages and disadvantages in clinical application in China.

\section{References}

1. Chambers HP (2001) The changing epidemiology of Staphylococcus aureus? Emerg Infect Dis 7: 178-182.
2. FP Hu, Y Guo, DM Zhu, Wang F, Jiang XF, et al. (2016) Resistance trends among clinical isolates in China reported from CHINET surveillance of bacterial resistance, 2005-2014. Clin Microbiol Infect 1: S9-S14.

3. Chen K, Huang Y, Song Q, Wu C, Chen X, et al. (2017) Drugresistance dynamics of Staphylococcus aureus between 2008 and 2014 at a tertiary teaching hospital, Jiangxi Province, China. BMC Infect Dis. 17: 97.

4. Que YA, Moreillon P (2009) Staphylococcus aureus. In Mandell GL, Bennett JE, Dolin R (eds.), Mandell, Douglas, and Bennett's principles and practice of infectious diseases, (7th edn) Churchill Livingstone, Philadelphia, PA.

5. Clinical and Laboratory Standards Institute (2015) Performance standard for antimicrobial susceptibility testing, 25th informational supplement, M100-S25. Wayne, PA: CLSI, 2015.

6. Hou X, Xiao M, Chen SC, Wang H, Cheng JW, et al. (2016) Identification and antifungal susceptibility profiles of Candida haemulonii species complex clinical isolates from a multicenter study in China. J Clin Microbiol 54: 2676-2680.

7. Gou YZ, Liu B, Pan L, Yu HT, Wang JP, et al. (2010) Pathogens of spontaneous bacterial peritonitis change in northern China. Saudi Med J 31: 1152-1156.

8. Kateete DP, Kimani CN, Katabazi FA, Okeng A, Okee MS, et al. (2010) Identification of Staphylococcus aureus: DNase and Mannitol salt agar improve the efficiency of the tube coagulase test. Ann Clin Microbiol Antimicrob 9: 23.

9. Clinical and Laboratory Standards Institutes Institute (2015) Performance standards for antimicrobial susceptibility testing; 25th informational supplement. CLSI document M7-A10 CLSI, Wayne, PA.

10. Russi NB, Maito J, Dieser SA, Renna MS, Signorini ML, et al. (2015) Comparison of phenotypic tests for detecting penicillin G resistance with presence of blaZ gene in Staphylococcus aureus isolated from bovine intramammary infections. J Dairy Res 82: 317-321.

11. Mittman SA, Huard RC, Della-Latta P, Whittier S (2009) Comparison of BD Phoenix to Vitek 2, MicroScan MICroSTREP, and Etest for antimicrobial susceptibility testing of Streptococcus pneumoniae. J Clin Microbiol 47: 3557-3561. 